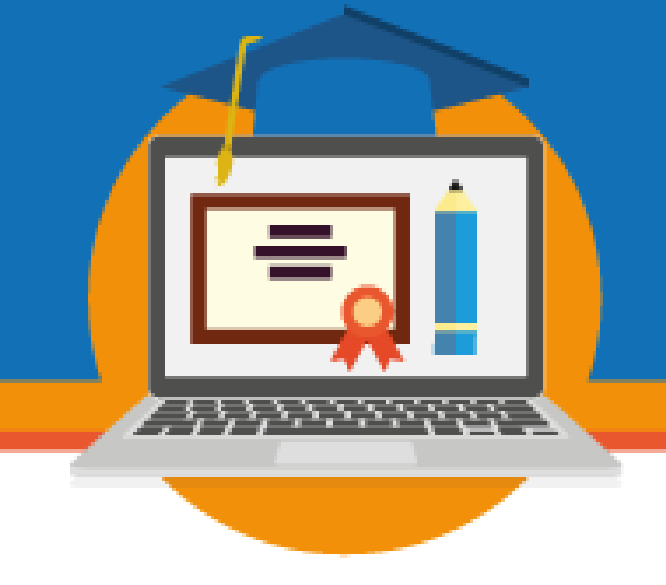

\title{
INTERATIVIDADE DA LOUSA DIGITAL NA EDUCAÇÃO INFANTIL COM A UTILIZAÇÃO DOS JOGOS ONLINE
}

\author{
Alfredo Souza de Oliveira \\ alfredo.oliviera@gmail.com \\ Universidade Católica Dom Bosco - Brasil \\ Mishelly Ocuda Henrique de Lima Tinôco \\ mishelly18@hotmail.com \\ Universidade Norte do Paraná - Brasil
}

\begin{abstract}
Resumo: Este artigo é resultado de uma aula realizada na II etapa da Educação Infantil. O objetivo geral foi: utilizar os recursos tecnológicos na educação infantil. Os objetivos específicos são: a) oportunizar a interatividade, percepção espacial estimulando a coordenação motora e o prazer em jogar utilizando as funcionalidades da lousa digital; b) contribuir no desenvolvimento social, motor fino, grosso, assimilação de cores e estabelecer algumas apropriações do cotidiano contemplando as formas geométricas na formação de crianças 03 a 04 anos; c) identificar os recursos tecnológicos do convívio dos alunos ressaltando sua funcionalidade. Espera-se que os recursos tecnológicos auxiliem na consolidação dos direitos de aprendizagem da educação infantil.
\end{abstract}

Palavras-chave: Lousa digital; Interatividade; Jogos on-line.

\section{INTRODUÇÃO}

A utilização dos recursos tecnológicos e os jogos on-line encontram-se mais frequente na vivência dos alunos desde o âmbito familiar ao cotidiano escolar, de certa forma esses recursos tornam as aulas mais atrativas oportunizando dinâmica, envolvimento e consolidação dos direitos de aprendizagem da educação infantil, estimulando aos alunos a interação social, buscando promover a ação concreta dos pilares da educação infantil: cuidar, educar e brincar.

Portanto, a inovação do fazer pedagógico na educação infantil não requer somente um ambiente agradável e aconchegante e sim inovador proporcionando ao seu desenvolvimento mídias atualizadas e atrativas, em vista de uma geração extremamente tecnológica onde a 


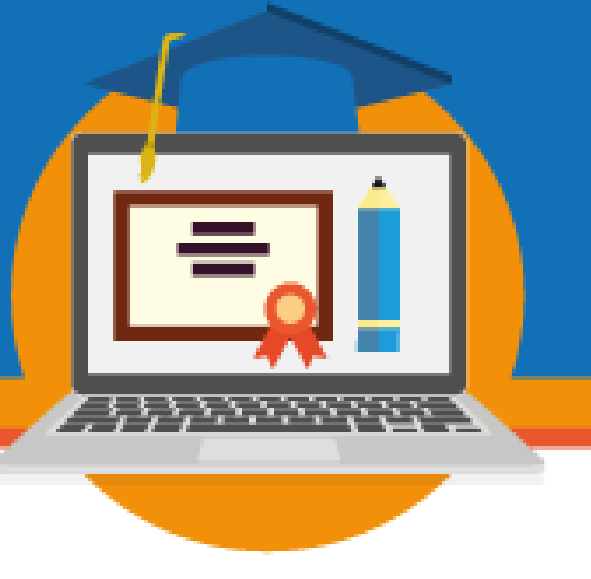

utilização da lousa digital concomitante aos jogos on-line da Discovery Kids oportunizou estímulo e envolvimento dos alunos, respeitando seus aspectos cognitivo, emocional e habilidades com os recursos tecnológicos. Assim, procedimentos de pesquisa foram de cunho bibliográfico, documental e de campo. As pesquisas documentais e bibliográficas consistiramse nas leituras analíticas das fontes primárias, secundárias e execução de um plano de aula na referida etapa de ensino.

Deste modo, este artigo está estruturado em três partes contemplando também o acervo fotográfico das atividades desenvolvidas em campo dividida em duas partes a primeira contempla a apresentação e interatividade dos recursos que foram trabalhados; a segunda parte ressalta a utilização da lousa digital nas atividades didático-pedagógicas, além da conclusão e referências na próxima seção. Será ressaltada um breve histórico da educação infantil mediante a utilização das mídias digitais.

\section{Breve histórico da educação infantil no contexto tecnológico.}

A educação infantil é a primeira etapa da educação básica torna - se obrigatória com base na Lei n. ${ }^{\circ}$ 12.796, de 4 de abril de 2013. Essa regulamentação oficializa a mudança feita na Constituição Federal por meio da Emenda Constitucional n. 59 em 2009, que tem por finalidade o desenvolvimento integral da criança a partir dos 04 (quatro) anos de idade, estar devidamente matriculada na educação básica art.6 sendo assim, seus aspectos físicos, psicológicos, intelectual e social, completando a ação da família e da comunidade art. 29.

Assim, nas Leis de Diretrizes e Bases (LDB), a expressão "primeira etapa da educação básica" incorporou à educação infantil uma etapa formal da educação escolar onde o desenvolvimento é pleno, direito à assistência integrada e integral, incluindo o acesso à educação e interatividade dos recursos disponíveis na sociedade em que o cerca.

Para que ocorra está vivência é necessária à [re] organização da estrutura e disponibilidade de recursos tecnológicos que possam envolver professores e alunos propiciando uma rotina que estimule o desenvolvimento e a aprendizagem do aluno favorecendo um espaço inovador e aguçante para novas descobertas. 


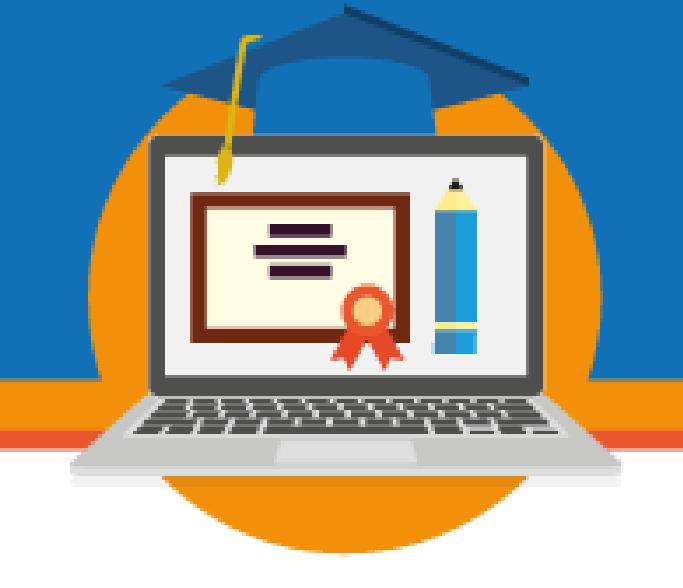

O espaço na instituição de educação infantil deve propiciar condições para que as crianças possam usufruí-lo em benefício do seu desenvolvimento e aprendizagem. Para tanto, é preciso que o espaço seja versátil e permeável à sua ação, sujeito às modificações propostas pelas crianças e pelos professores em função das ações desenvolvidas. (BRASIL: RCNEI, 1998, p.69)

Piaget afirma que, a criança aprende construindo e reconstruindo seu pensamento mediante a assimilação, acomodação e estrutura oferecida a ela em seu estágio simbólico na faixa - etária de dois a sete anos refletindo o egocentrismo e a dinâmica de socialização por meio de desenhos, atitudes estando vinculado ao mundo concreto.

Para Wallon, os principais elementos desta fase na educação infantil é a afetividade, o movimento, a inteligência e a formação do ser como pessoa, desde que a escola ofereça formação integral, intelectual afetiva e social proporcionando situações epistemológicas criando a apropriação do conhecimento no contexto escolar.

Segundo Mello e Vicária (2008, p. 486), apud Gomes (2011, p.272):

\begin{abstract}
Crianças com menos de dois anos já se sentem atraídas por vídeos e fotos digitais. A intimidade com o computador, porém, costuma chegar aos quatro anos. Nessa idade, já deslizam o mouse olhando apenas para o cursor na tela. Aos cinco, reconhecem ícones, sabem como abrir um software e começam a se interessar pelos primeiros jogos virtuais, como os de associação ou de memória. (MELLO e VICÁRIA, 2008, p. 486).
\end{abstract}

Nesse sentido, o principal elo entre a infância e o futuro é o fortalecimento da própria infância, cuidando para que esse tempo único, marcante e curto seja plenamente vivido e usufruído ressaltando o papel da escola propiciando aos alunos diversas tecnologias digitais, oferecendo meios para que os mesmos possam acompanhar parte das inovações tecnológicas através da mediação dos professores participantes deste processo de inovação e do fazer pedagógico nas salas de educação infantil. Assim, na próxima seção apresenta-se uma minuta da lousa digital e as possibilidades metodológicas na educação infantil por intermédio das referências bibliográficas.

\title{
2. Lousa digital como recurso didático - metodológico na educação infantil.
}

$\mathrm{O}$ avanço dos recursos tecnológicos vem sendo marcado pela crescente agilidade e atualização das informações, tornando-se indispensável na educação, tendo como contribuição 


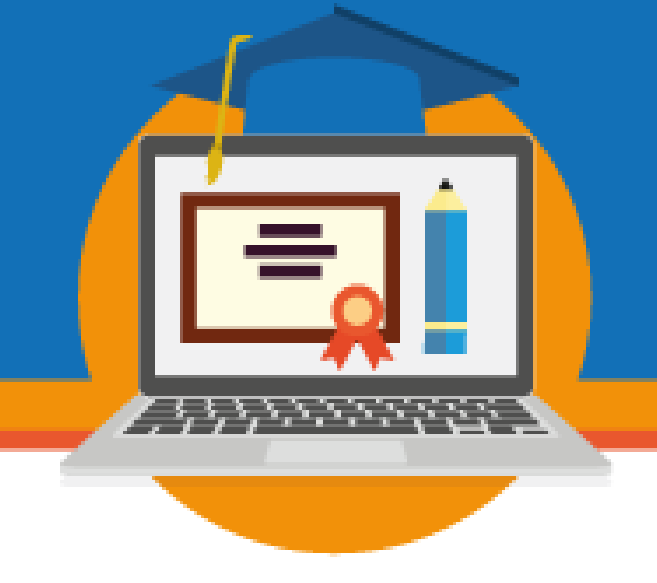

nas atividades didático-pedagógicas e com inúmeras possibilidades de utilizá-las e disponibilizá-las no âmbito educacional.

Em vista deste avanço e vivência, o Fundo Nacional de Desenvolvimento da Educação (FNDE) realizou no ano de 2011 o processo de entrega das lousas digitais pregão 72/2011 nas escolas públicas a nível de Brasil para complementar o computador interativo (ProInfo Integrado), a mesma possui um layout facilitador e funcional nas atividades diárias do âmbito escolar e recentemente a Secretaria de Estado de Educação apostou na tecnologia como aliada à prática pedagógica e iniciou um projeto com a utilização de lousa digital no Centro de Educação Infantil José Eduardo Martins Jallad (CEI Zedu), localizado no município de Campo Grande.

Para tanto, as unidades escolares que receberam este recurso tecnológico desenvolveram propostas didático-pedagógicas nas diversas etapas de ensino dispondo das funcionalidades e simultaneidade do universo on-line.

[...] um mundo virtual, no sentido amplo, é um universo de possíveis, calculáveis a partir de um modelo digital. Ao interagir com o mundo virtual, os usuários o exploram e o atualizam simultaneamente. Quando as interações podem enriquecer o modelo, o mundo virtual torna-se um vetor de inteligência e criação coletivas. (LÉVY, 2010, p. 75).

Dentre as etapas de ensino, na rede estadual de educação por não dispor de educação infantil no município de Corumbá, vi a possibilidade de oportunizar o recurso lousa digital na educação infantil, em uma escola da rede privada de ensino.

A fim de que os alunos, vivenciassem a interatividade dos jogos on-line por meio da lousa digital, buscando estimular a utilização das tecnologias digitais no âmbito da educação infantil.

Kenski (2007) afirma que, o pedagogo que conforme o termo encaminhe e oriente o aluno diante das diversas possibilidades e formas de se interagir e conquistar o conhecimento.

Nesta perspectiva, a facilidade do acesso à informação oportuniza-se na formação da criança mediante conhecimento prévio oportunizado pela sociedade, dentre a vivência familiar, escolar e mídias que a cercam. Portanto, é de suma importância que a criança seja estimulada e orientada na utilização adequada dos recursos tecnológicos disponíveis em sua rotina, cabendo ao professor associar as tecnologias para a valorização da aprendizagem dos alunos independente de sua faixa- etária ou etapa de ensino. Deste modo, a seção a seguir, apresenta 


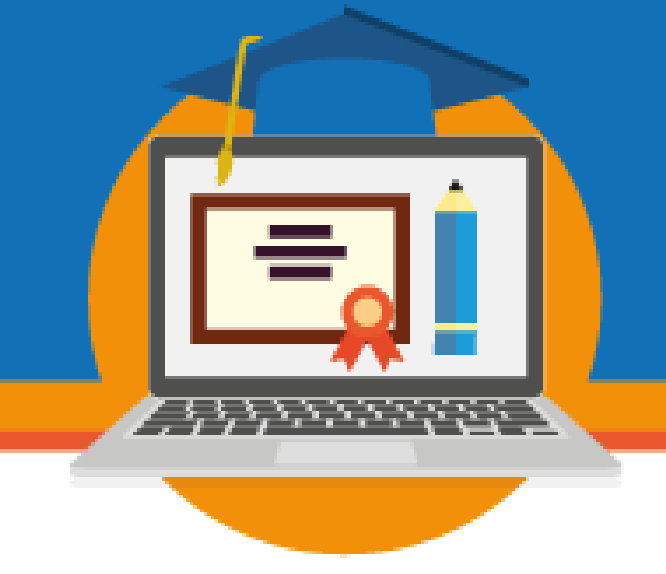

os resultados da utilização da lousa digital na educação infantil, juntamente com as etapas do plano de aula e o acervo fotográfico na execução do mesmo.

\section{Resultados e discussões da utilização da lousa digital na educação infantil.}

Mediante está facilidade a lousa digital foi utilizada como ação pedagógica do Colégio Salesiano de Santa Teresa para interatividade dos alunos do nível II com a faixa etária de 03 a 04 anos, os alunos não têm acesso diário com a lousa digital e demonstraram familiaridade com as funcionalidades.

As tecnologias digitais estão realizando transformações profundas nos processos de aprendizagem e nas mudanças da escola. Reflete que o uso das tecnologias na educação propicia a interdisciplinaridade, uma organização heterárquica, estimula a participação cooperativa e solidária, promove a autonomia e a responsabilidade da autoria nos alunos. (FAGUNDES, 2007, p. 14).

Os jogos foram selecionados mediante a faixa etária, buscando facilitar a utilização da lousa com os jogos online, para tanto, os alunos apesar da idade e por nunca ter utilizado a lousa digital demonstraram domínio e agilidade com a caneta ao utilizar as funcionalidades da lousa.

Entretanto, é necessário o envolvimento das tecnologias no cotidiano dos alunos no âmbito escolar, mediante que as tecnologias digitais estão presentes a todo instante na vivência dos mesmos, sendo a escola como mediadora do repensar as práticas e de orientar o aluno ao exercício da cidadania.

A escola representa na sociedade moderna o espaço de formação não apenas das gerações jovens, mas de todas as pessoas. Em um momento caracterizado por mudanças velozes, as pessoas procuram na educação escolar a garantia de formação que lhes possibilite o domínio de conhecimentos e melhor qualidade de vida. (KENSKI, 2007, p. 8).

Foto 1: Narrativa do texto: Dom Caranguejo. 


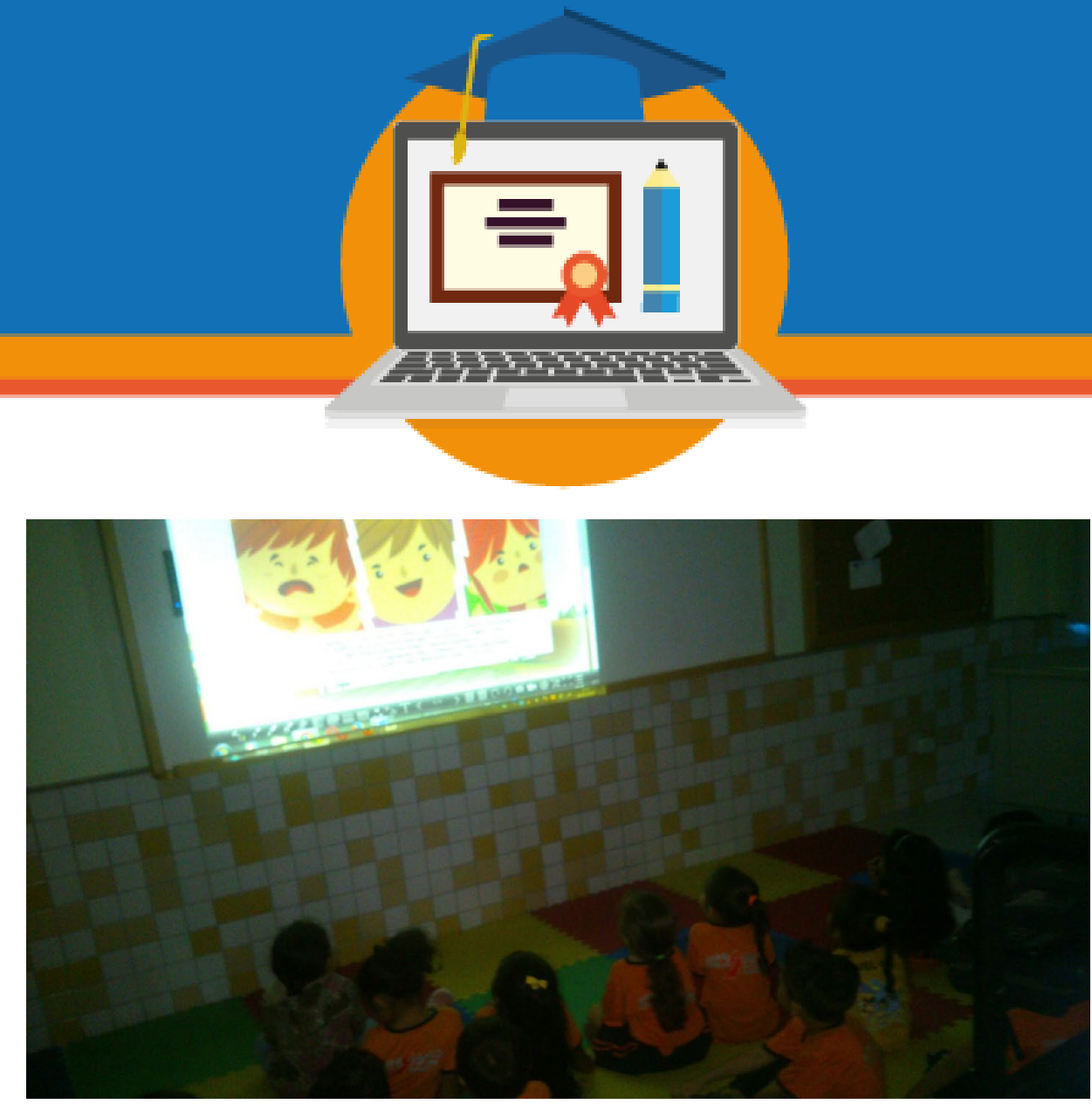

Fonte: Acervo fotográfico no desenvolvimento das atividades.

Na foto 1, a turma ouviu a história do Dom Caranguejo a mesma ressalta um grupo de crianças em período de férias e utiliza uma máquina digital para fazer o registro dos momentos mais importantes de sua viagem à praia. Após a história os alunos foram estimulados a responder se já utilizaram a máquina digital e quais momentos registram com a utilização da mesma? Onde tiraram foto? Qual é a foto que você acha mais legal? Vocês utilizam celular para registrar esses momento também?

Mediante as respostas dos alunos observa-se que as tecnologia estão presentes na vivência dos alunos e sabem identificar que o mesmo serve como apoio para registros diários.

Foto 2: Interatividade do jogo da memória Luna. 


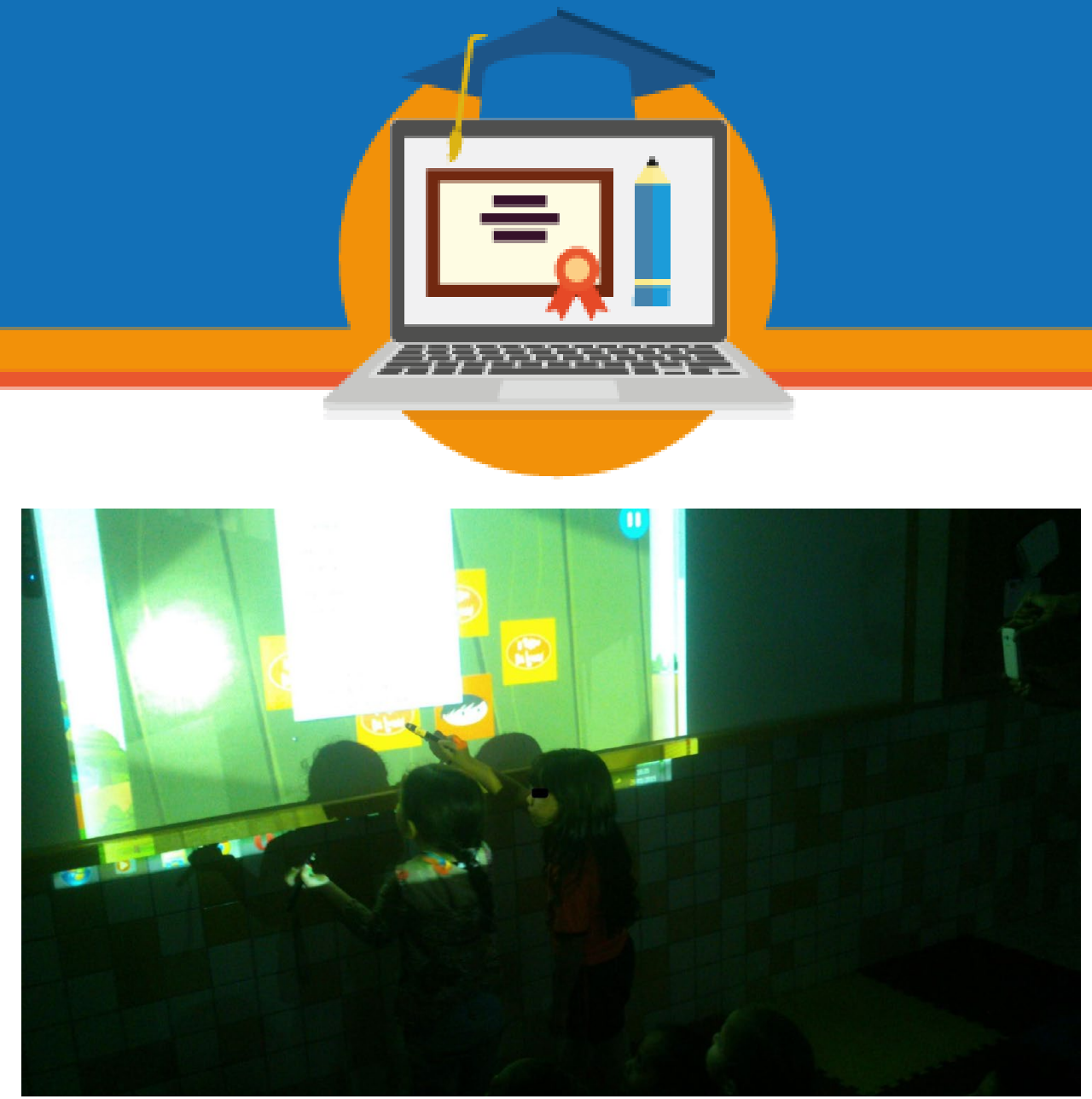

Fonte: Acervo fotográfico no desenvolvimento das atividades.

$\mathrm{Na}$ foto 2, apresenta aos alunos na interatividade da lousa digital a calibração da caneta, e como iriamos utilizar a lousa digital com os jogos on-line do site Discovery Kids. Sendo o primeiro jogo da memória da Luna, proporcionando aos alunos melhor percepção da coordenação motora fina para utilizar a caneta e estimular a percepção de memória de forma simultânea.

O segundo jogo foi estimular aos alunos a encaixar as formas no lugar certo, ressaltando indagações de onde podemos encontrar essas formar no cotidiano. O terceiro foi siga o som, conforme os desenhos que aparecem na tela eles clicaram conforme a sequência e o último jogo foi pintura online da personagem Peppa e a turma do Peixonauta.

Para melhor compreensão das atividades desenvolvidas, segue nesta seção o planejamento utilizado na respectiva turma da educação infantil.

Planejamento da atividade desenvolvida.

\section{Colégio Salesiano de Santa Tereza}

Corumbá, 29 de maio de 2015.

\section{Atividade educacional} Mãe talentosa 


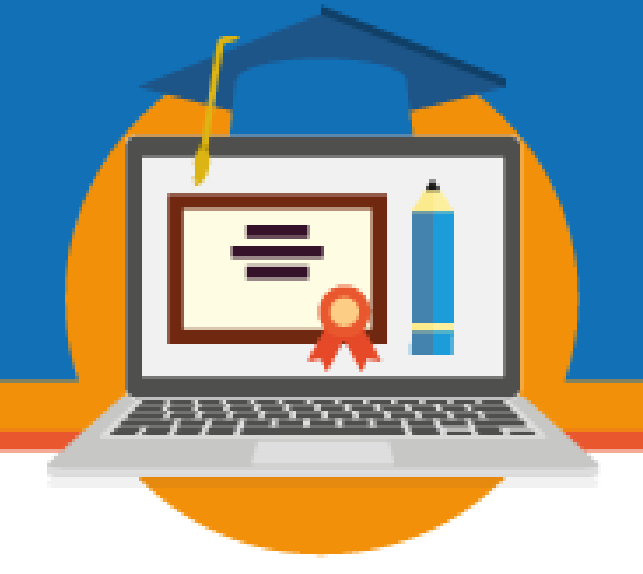

A presente atividade propõe o estímulo em utilizar os recursos tecnológicos na educação infantil, às tecnologias digitais busca incorporar na proposta pedagógica as hipóteses construtivistas tornando possível a interação e novas vivências.

\section{Bloco de conteúdo:}

Conteúdo: Artes, História, matemática e musicalidade.

Introdução: Utilização da lousa digital nas atividades didático - pedagógico da educação infantil

\section{Objetivo:}

* Estimular a memorização;

* Reconhecer as cores sugeridas;

* Identificar a sequência de sons;

* Despertar emoções;

* Envolver o pensamento e a linguagem com a história Dom Caranguejo:

\section{Tempo estimado: 3 aulas}

Material necessário: Caixa de som, lousa digital, data show e notebook.

\section{Desenvolvimento das atividade}

$\mathbf{1}^{\mathbf{0}}$ momento - Acolhida receber os alunos (as) com a história Dom Caranguejo valorizando o uso das tecnologias para utilização do registro.

$2{ }^{\text {0 }}$ momento - Após assistir o vídeo Dom Caranguejo oportunizar uma roda de conversa, perguntando os lugares que os alunos (as) já passearam ou gostam de ir;

$3^{\mathbf{0}}$ momento - Nortear os alunos para interatividade com a lousa digital e o jogo da memória da Luna http://discoverykidsbrasil.uol.com.br/jogos/luna-jogo-da-memoria/, o mesmo apresenta lugares diversificados utilizando os recursos da lousa digital.

$\mathbf{4}^{\mathbf{0}}$ momento - Oportunizar aos alunos (as) o jogo formas http://discoverykidsbrasil.uol.com.br/jogos/peggato-jogodasformas/, ressaltando as diversas formas que vimos no nosso cotidiano;

$5^{\mathbf{0}}$ momento - Estimular os alunos com a atividade siga o som http://discoverykidsbrasil.uol.com.br/jogos/pistas-musicais/.

$\mathbf{6}^{\mathbf{0}}$ momento - Propor a atividade de pintura online http://discoverykidsbrasil.uol.com.br/jogos/peggato-jogodasformas/ com a utilização da lousa digital. 


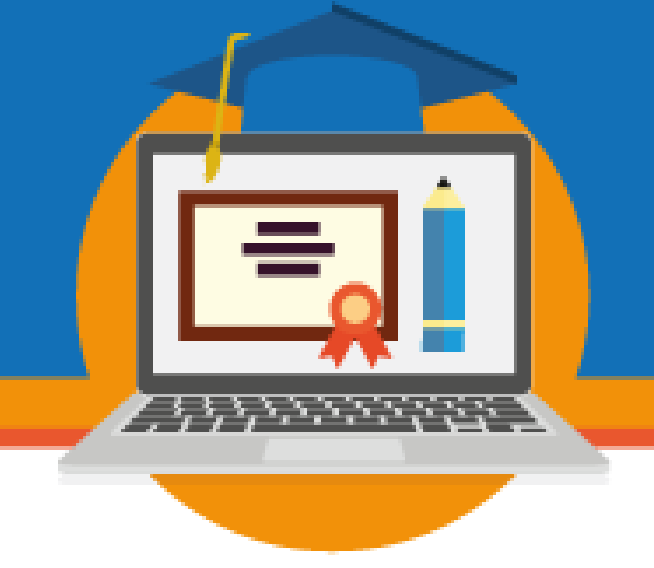

Avaliação: Será avaliada a participação dos alunos (as) na aula, os questionamentos e reconhecimento das atividades propostas.

\section{Referências}

http://discoverykidsbrasil.uol.com.br/jogos/dom-caranguejinho/ História http://discoverykidsbrasil.uol.com.br/jogos/luna-jogo-da-memoria/ - Jogo da memória Luna http://discoverykidsbrasil.uol.com.br/jogos/pistas-musicais/ siga o som http://discoverykidsbrasil.uol.com.br/jogos/peixtronauta-vamos-pintar/ - pintar http://discoverykidsbrasil.uol.com.br/jogos/peggato-jogodasformas/ - formas

\section{CONCLUSÃO}

Considera-se que os alunos do nível II do Colégio Salesiano de Santa Teresa possuem familiaridade com os recursos tecnológicos cabendo à escola como organizadora do espaço pedagógico e professores que oportunizem e direcionem essas tecnologias no cotidiano das tarefas a serem desenvolvidas no universo virtual.

A escola necessita estimular outros ambientes de aprendizagem tornando-se necessário traçar novas perspectivas pedagógica, a fim de despertar nos alunos da educação infantil a curiosidade e a habilidade de criar com a utilização dos recursos tecnológicos, em meio à termologia atual, a criança é entendida como indivíduo que necessita desenvolver e acompanhar as tecnologias levando em consideração sua geração e seu convívio com estes recursos dentro e fora do contexto educacional.

As propostas didático-pedagógicas mediante as tecnologias precisam ser [re] vista como forte aliada nas metodologias aplicadas pelo professor contribuindo para as modificações do contexto da aprendizagem dos alunos da educação infantil, conscientizando que os recursos tecnológicos estão a favor do incentivo à criação e a pesquisa, buscando nortear a formação dos alunos para o senso crítico criativo perceptivo na construção do conhecimento, desafiando as novas práticas na referida unidade escolar. 


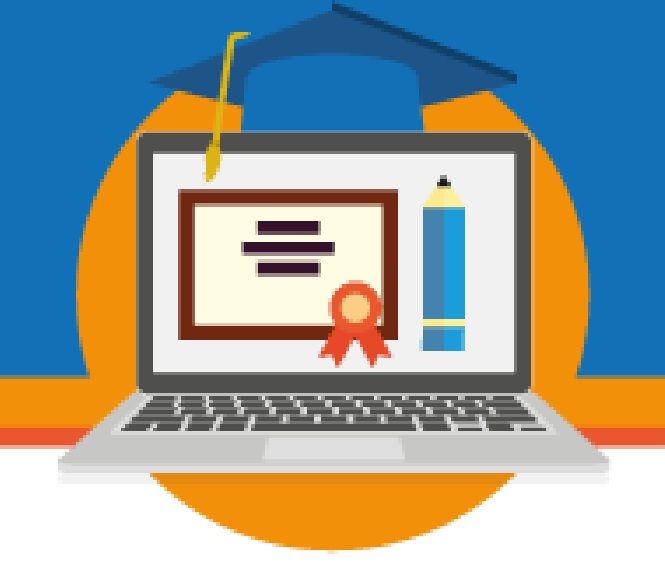

\section{REFERÊNCIAS}

Piaget. J. A Vida e o Pensamento do Ponto de Vista da Psicologia Experimental e da Epistemologia Genética. In. Piaget. Rio de Janeiro: Forense Universitária.

Piaget. J. A Epistemologia Genética. Trad. Nathanael C. Caixeira. Petrópolis: Vozes, 1971. $110 \mathrm{p}$

BRASIL. Lei de Diretrizes e Bases da Educação Nacional. Lei 9394/96 de 20 de dezembro de 1996.

. Ministério da Educação e do Desporto. Secretaria da Educação Fundamental. Referencial Curricular Nacional para a Educação Infantil. Documento Introdutório. Brasília: MEC/SEF, 1998. v. 1

LÉVY, Pierre. Cibercultura. 3 ed. São Paulo, 2010.

FAGUNDES, Lea. O professor deve tornar-se um construtor de inovações -entrevista Midiativa, 2007.

KENSKI, Vani Moreira. Novas tecnologias, o redimensionamento do espaço e do tempo e os impactos no trabalho docente. Disponível em $<$ http://www.ufba.br/ prossiga/vani.htm $>$. Acesso em 11/10/2015. 